\title{
Understanding Revised NAAC Grading Pattern
}

\section{OPEN ACCESS}

Manuscript ID:

ASH-2020-08013081

Volume: 8

Issue: 1

Month: July

Year: 2020

P-ISSN: 2321-788X

E-ISSN: 2582-0397

Received: 20.04.2020

Accepted: 16.06.2020

Published: 02.07.2020

Citation:

Alhat, Swapnil S.

"Understanding Revised NAAC Grading Pattern." Shanlax International

Journal of Arts, Science and Humanities, vol. 8, no. 1, 2020, pp. 57-60.

DOI:

https://doi.org/10.34293/ sijash.v8i1.3081

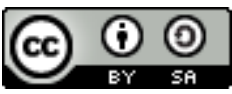

This work is licensed under a Creative Commons Attribution-ShareAlike 4.0 International License

\author{
Swapnil S Alhat \\ Lecturer, Post-Graduate Department of English \\ LVH College, Nashik, Maharashtra, India \\ https://orcid.org/0000-0002-3668-6484
}

\begin{abstract}
National Assessment and Accreditation Council (NAAC), an autonomous institution of University Grant Commission (UGC), it has been merely 26 years since the inception of NAAC, whose Accreditation to Higher Education Institutions (HEIs) in India is mandatory likewise only a NAAC Accredited higher learning institutions are eligible for UGC and other various grants. Moreover, $N A A C$ accreditation determines the quality of the institute in terms of education, infrastructure, research, teaching \& learning, etc.NAAC Accreditation helps a learning institution to know its strengths, weaknesses, and opportunities through the various review process, likewise in initiating modern pedagogical methods and in receiving grants from the Government's various bodies. Importantly, it helps students to know details of the educational institution in terms of infrastructure, quality of education, research output, etc. Therein, NAAC Accreditation is indispensable to HEIs in India, and this paper, the prime focus of research has been to unravel the revised NAAC Grading Pattern because, in the end, a 'Grade' determines the quality of an institution.
\end{abstract}

Keywords: Higher Education Institutions (HEIs), NAAC Criteria, NAAC Grading Pattern, Calculations of Institutions CGPA, Assessment Outcome, NAAC Peer Team Report and Specimen Grade Sheet

\section{Introduction}

National Assessment and Accreditation Council, many in academia, is familiar with mostly its abbreviation NAAC. The job of the NAAC is to assess and accredit the quality of Higher Education Institutions (HEIs) in India. Moreover, the NAAC is mandatory for all HEIs in India. India is a very diverse country not only culturally and linguistically but education-wise as well. It is an outcome of the recommendations made by National Education Policy (1986) and the Programme of Action (POA) 1992, which advocated the establishment of a national accreditation body, thus on16 September 1994 NAAC came into existence, viz. headquarter in Bangalore.

Since its inception, the NAAC has accepted changes and molded itself according to the changing time. NAAC made an upside-down change in its Assessment and Accreditation (A\&A) methodology which came into effect from 1 July 2016 and later on in July 2017 Revised Assessment and Accreditation (A\&A) Framework was launched, which introduce pre-qualifiers score before peer team visit, an institution must $30 \%$ of system generated score to be eligible for peer team visit for which HEIs must submit online their Self Study Report (SSR) and Student Satisfactory Survey (SSS). NAAC, for the first time, introduced a System Generated Scores (SGS) with online evaluation up to $70 \%$ and Peer Team evaluation 30\%. 
NAAC has Divided HEIs into Three Types

- Universities (Central/State/Private/Considered) and National Major Institutions

- Autonomous Colleges / Constitutional Colleges / Affiliated Colleges (affiliated to UGC approved universities)
- Accredited HEIs that apply to accredited reevaluation or subsequent cycles (cycle 2 , cycle 3 , cycle 4).

Moreover, any HEIs which have completed six years are eligible for Assessment and Accreditation.

NAAC has developed seven different Criteria for the Assessment of HEIs, which is as follows:

\begin{tabular}{|c|l|c|c|c|}
\hline S. No. & Criteria & University & Autonomous College & Affiliated College \\
\hline 1 & Curricular Aspect & 150 & 150 & 100 \\
\hline 2 & Teaching Learning and Evaluation & 200 & 300 & 350 \\
\hline 3 & Research, Innovations and Extensions & 250 & 150 & 120 \\
\hline 4 & Infrastructure and Learning Resources & 100 & 100 & 100 \\
\hline 5 & Student Support and Progression & 100 & 100 & 130 \\
\hline 6 & Government Leadership and Management & 100 & 100 & 100 \\
\hline 7 & Institutional Values and Best Practices & 100 & 100 & 100 \\
\hline & Total Score & 1000 & 1000 & 1000 \\
\hline
\end{tabular}

Old Grading Pattern of NAAC (before 2014 and was in effect from 1 April 2007)

\begin{tabular}{|c|c|l|}
\hline $\begin{array}{c}\text { Range of Institutional Cumulative Grade Point } \\
\text { Average (CGPA) }\end{array}$ & Letter Grade & \multicolumn{1}{|c|}{ Performance Descriptor } \\
\hline $3.01-4.00$ & $\mathrm{~A}$ & Very Good (Accredited) \\
\hline $2.01-3.00$ & $\mathrm{~B}$ & Good (Accredited) \\
\hline $1.51-2.00$ & $\mathrm{C}$ & Satisfactory (Accredited) \\
\hline$\leq 1.50$ & $\mathrm{D}$ & Unsatisfactory (Not-accredited) \\
\hline
\end{tabular}

Revised Grading Pattern of NAAC from $1^{\text {st }}$ July 2016

\begin{tabular}{|c|c|c|}
\hline $\begin{array}{c}\text { Range of Institutional } \\
\text { Cumulative Grade } \\
\text { Point Average } \\
\text { (CGPA) }\end{array}$ & $\begin{array}{c}\text { Letter } \\
\text { Grade }\end{array}$ & Status \\
\hline $3.51-4.00$ & $\mathrm{~A}++$ & Accredited \\
\hline $3.26-3.50$ & $\mathrm{~A}+$ & Accredited \\
\hline $3.01-3.25$ & $\mathrm{~A}$ & Accredited \\
\hline $2.76-3.00$ & $\mathrm{~B}++$ & Accredited \\
\hline $2.51-2.75$ & $\mathrm{~B}+$ & Accredited \\
\hline $2.01-2.50$ & $\mathrm{~B}$ & Accredited \\
\hline $1.51-2.00$ & $\mathrm{C}$ & Accredited \\
\hline$\leq 1.50$ & $\mathrm{D}$ & Not-accredited \\
\hline
\end{tabular}

Institution which secures CGPA equal or less than 1.50 are categorized under the " $\mathrm{D}$ " Category and notified by NAAC as "Assessed and Found not qualified for Accreditation."

\section{Calculation of Institutional CGPA}

The CGPA is calculated based on three sources. Namely, the System Generated Scores (SGS) of quantitative measures, which comprise $70 \%$ of the total, the quality of the on-site peer group student satisfaction survey, the critical assessment scores and the scores obtained. These will be collated through an automated method based on 'benchmarks' and evaluated on a five-point scale.

\section{Assessment Outcome}

A Peer Team nominated by NAAC visits the HEIs for onsite assessment and focuses on the information provided by the HEIs on the qualitative metrics. The institution submits SSR and the complied SSR are used for onsite assessment:

- An Onsite assessment of the qualitative components of the SSR by a visiting team resulting in the generation of a qualitative report of the institution identifying the strengths, weaknesses, opportunities, and challenges(SWOC) and 
assigning scores as per the performance on each of the qualitative metrics.

- On completion of onsite evaluation NAAC combines the scores assigned by the teams, the pre-qualifier scores, and the SSS to arrive at overall Criterion wise Grade Point Averages (CrGPA).

- The outcome is placed for approval of the Executive council of NAAC before declaring the Accreditation status and the institutional Grade.

Based on the size and scope of academic offerings at the HEIs, the number of days and experts for an onsite visit may vary from 2-3 days with 2-5 expert reviewers visiting the institutions.

After the thorough inspection, the final report is given by a peer team of their Assessment Accreditation, which is a combination of qualitative and quantitative metrics, and this compiled in three parts as follows:

\section{Part I - Peer Team Report}

Section 1: Gives the General Information of the Institution and its contexts.

Section 2: Gives Criterion wise analysis based on peer evaluation of qualitative indicators. It is a qualitative, descriptive assessment report based on the Peer Team's critical analysis presenting strengths and weaknesses $\mathrm{f}$ the HEIs under each Criterion.
Section 3: Presents an Overall Analysis, which includes Institutional Strengths, Weaknesses, Opportunities, and Challenges.

Section 4: Records Recommendations for Quality Enhancement of the Institution (not more than 10).

\section{Part II - Graphical Presentation Based on Quan- titative Metrics $\left(\mathbf{Q}_{\mathbf{n}} \mathbf{M}\right)$}

This is a System Generated Quality Profile of HEIs based on the statistical analysis of quantitative indicators in the NAAC's Quality Indicator Framework (QIF).

\section{Part III - Institutional Grade Sheet}

This part contains the Institutional Grade Sheet. It is based on the Qualitative Indicators, Quantitative Indicators, and Students Satisfactory Survey using existing calculating methods, which is generated by the software.

Final Outcome of the NAAC Peer Team visit Concluded in conferring Grade to the HEIs:

Specimen Grade Sheet (Affiliated College)

(For Universities and Autonomous Colleges weights differs)

Name of the Institution: Bose College

Place: Ramnagar [MS]

Date of Visit: 2 February to 4 February 2019

\begin{tabular}{|l|c|c|c|}
\hline \multicolumn{1}{|c|}{ Criteria } & Weightage (Wi) & $\begin{array}{c}\text { Criterion Wise } \\
\text { Weighted Grade } \\
\text { Points (CrWGP i) }\end{array}$ & $\begin{array}{c}\text { Criterion Wise } \\
\text { Grade Point Average } \\
\text { (CrWGP i / Wi) }\end{array}$ \\
\hline I Curricular Aspects & 100 & 210 & 2.10 \\
\hline II Teaching Learning and Evaluation & 350 & 950 & 2.71 \\
\hline III Research Consultancy and Extension & 150 & 480 & 3.2 \\
\hline IV Infrastructure and Learning Resources & 100 & 270 & 2.70 \\
\hline V Student Support Progression & 100 & 290 & 2.90 \\
\hline VI Governance, Leadership and Management & 100 & 190 & 1.90 \\
\hline VII Innovations and Best Practices & 100 & 210 & 2.10 \\
\hline & $\sum_{i=1}^{7} W i=1000$ & $\sum_{i=1}^{7}($ CrWGPi) $=2600$ & \\
\hline
\end{tabular}

$$
\begin{aligned}
\text { Institutional CGPA } & =\frac{\sum_{i=1}^{7}(C r W G P i)}{\sum_{i=1}^{7} W i} \\
& =2600 / 1000=2.6
\end{aligned}
$$

Grade: B+

\section{Conclusion}

The old Grading Pattern of NAAC Assessment and Accreditation (A\&A) was rigid and inflexible likewise provided limited opportunities for smaller 
and semi-urban and rural HEIs to secure higher Grade in NAAC Accreditation thereof many HEIs had secured either B or C Grade in pre-revised framework. But, this revised Grading Pattern of NAAC Accreditation provides ample of opportunities to all the Urban, Semi-urban and Rural, Autonomous Institutions and Universities (Central/State) to secure higher Grade. Thus, the revised NAAC framework is more flexible and easily comprehensible and provides equal opportunities to all HEIs in a way NAAC has truly democratized the Assessment and Accreditation (A\&A) process.

\section{References}

Assessment \& Accreditation, National Assessment and Accreditation Council, 2018.

Grading System of NAAC, http://www.naac.gov.in/ docs/Grading_System.pdf

Guidelines for NAAC Financial Assistance for Assessment and Accreditation of Higher Education Institutions, National Assessment and Accreditation Council, 2016.

http://naac.gov.in/images/docs/NAAC $\% 20$

Brochure_2018.pdf
Institutional Accreditation Guidelines to the Peer

Team, National Assessment and Accreditation Council, 2016.

Kumar, Sakunth. NAAC - An Overview, Top NAAC Colleges \& Universities, Benefits, Grading System, 2020, https://www.collegedekho. com/articles/national-assessment-andaccreditation-council-naac/

Manual for Universities (Effective from July 2017), National Assessment and Accreditation Council, 2017.

Mehta, Goverdhan, and H.A. Ranganath. NAAC Profile, National Assessment and Accreditation Council, 2010.

Notice - Implementation of revised Grading System of NAAC, National Assessment and Accreditation Council, 2016, http://naac. gov.in/docs/Archives/General\%20Archive/ NOTICE-Revised\%20grading\%20system. pdf.

Revised Accreditation Framework, National Assessment and Accreditation Council, 2017.

\section{Author Details}

Swapnil S Alhat, Lecturer in English, Post-Graduate Department of English, LVH College, Nashik, Maharashtra, India,Email ID: www.swapnilalhat@gmail.com 